\title{
Iliak Arter Homogrefti ile Tekrarlayan Popliteal Arter Anevrizma Tamiri
}

\section{Recurrent Popliteal Aneurysm Repair Using Homograft Iliac Artery}

\author{
Abdullah Özer, Barış Mardin, Başak Koçak, Arif Özbay, Erkan İriz
}

Gazi Üniversitesi Tıp Fakültesi Kalp ve Damar Cerrahisi Anabilim Dalı, Beşevler, Ankara, Türkiye

\section{ÖZET}

Anevrizma, vücuttaki herhangi bir damarın çapında meydana gelen artışla birlikte duvarında incelme olması anlamına gelir. Sıklıkla belirti vermezler. Aort ve intrakranial arterler başta olmak üzere rüptüre olduklarında ciddi mortalite riskleri vardır ve bu nedenle çeşitli tedavi kılavuzları hazırlanmıştır. Popliteal anevrizmaların cerrahi tamirinde ven grefti, sentetik greft, homogreftler ve endovasküler tedavi gibi seçenekler bulunmaktadır. Biz de bu yazımızda homogreft yöntemle tedavi ettiğimiz bir olguyu siz değerli meslektaşlarımızın bilgisine sunmak arzusundayız.

Anahtar Sözcükler: Popliteal arter anevrizması, homogreft, periferik arter cerrahisi

Geliş Tarihi: 11.04.2019
Kabul Tarihi: 26.05.2020

\section{ABSTRACT}

Aneurysm definition includes widening of any blood vessel's diameter and slimming of the vessel's wall at the same time. They are mostly asymptomatic. They bear serious risk of mortality especially when they are present at aorta and intracranial arteries, thus treatment and management guides had been prepared. For surgical treatment of popliteal aneurysms, there are several options including venous grafts, synthetic grafts, homografts and endovascular treatment. In this report, we want to present a case which we used homograft for treatment, to you, our valuable colleagues.

Key Words: Popliteal artery aneurysm, homograft, peripheral vascular surgery

Received: 04.11 .2019

Accepted: 05.26.2020 


\section{GiRiş}

Arteriyel anevrizma tanımı, vücuttaki herhangi bir arterin, tüm duvar katmanlarını içerecek biçimde incelmesine verilen isimdir. Yalancı anevrizma ise arter duvarındaki tüm katmanların tutulmadığı, sıklıkla adventisya ve media katmanları içerisine dolan kan nedeniyle anevrizma benzeri bir görünüm oluştuğu durumları tanımlar (1). Gerçek anevrizmalarda duvardaki incelme nedeniyle kanın lineer akım düzeni bozulur ve bu durum tromboza ve distal emboliye neden olabilir. Ayrıca anevrizma duvarında artan stres nedeniyle rüptür riski de $\operatorname{artar}(2)$. Popliteal anevrizma, popliteal arterde oluşan anevrizma anlamına gelir. Bu bölgede oluşan anevrizmaların başlıca nedenleri, spontan, travmatik, dejeneratif, enfeksiyöz gibi sıkça karşılaşılan nedenlerdir. Bunlardan başka genetik, ilaç kullanımına bağı, iatrojenik gibi daha nadir nedenler de bulunmaktadır(3). Popliteal anevrizmalar sıklıkla herhangi bir belirti vermezler ancak tromboz, distal emboli, çok büyük anevrizmalarda fleksiyon kısıtılığı ve rüptür gibi ciddi belirtiler görülmesi olasıdır(3). Bu nedenle karşılaşıldığında tedavi edilmesi önerilmektedir. Tedavi seçenekleri arasında açık cerrahi düzeltme ya da endovasküler yöntemler tercih edilebilir(4).

\section{OLGU SUNUMU}

16 yaşında, bilinen başka hastalığı olmayan, 6 yıl önce travma nedeniyle popliteal arter cerrahisi geçiren hasta rutin kontrollerinde sağ popliteal arter anevrizması saptanması nedeniyle kliniğimize başvurdu. Hastanın özgeçmişinde ek hastalık saptanmadı. 2012 yılında travma sonrası popliteal arter yaralanması olan hastaya otolog safen ven ile patch-plasti yapıldığı öğrenildi. Herhangi bir şikayeti olmamasına karşın rutin kontrollerinde giderek artan çapa sahip popliteal anevrizma saptandığı öğrenildi. Fizik muayenesinde anormal bulgu saptanmadı. BT anjiografi görüntüsünde sağ popliteal arterin distal femur epifizine komşuluk gösteren bölgede $4 \mathrm{~cm}$ uzunluğunda en geniş yerinde $17 \mathrm{~mm}$ çapa sahip anevrizma olduğu görüldü. Hasta cerrahi düzeltme yapılması amacıyla yatırıldı. Hazırıkları tamamlanarak anestezi onayı alındıktan sonra hastanın ameliyatına başlandı.

Posterior yaklaşımla eski insizyon hattı açılarak sağ popliteal arter ve anevrizma bulundu. Anevrizmanın gerekli ölçümleri yapıldı (Resim-1,2). Proksimal ve distal akım kontrolü sağlanarak anevrizmatik kese eksize edildi (Resim-3). 10 yaşındaki bir hastadan alınan iliak homogreft ile popliteal interpoziyon (Resim -4) yapıldıktan sonra akım ve kanama kontrolü yapıldı. Proksimal ve distalde pulsatil akım gözlendi, herhangi bir kanama veya sızıntı saptanmadı. Çevre dokuların kanama kontrolü yapılarak dren kanülü yerleştirildi ve katlar kapatılarak operasyon sonlandırıldı. Postoperatif dönemde erken mobilizasyon uygulandı, yara bakımı ve pansumanı yapıldı, rutin kan kontrolleri yapıldı. Herhangi bir sorun gözlenmeyen hasta postoperatif ikinci günde taburcu edildi.

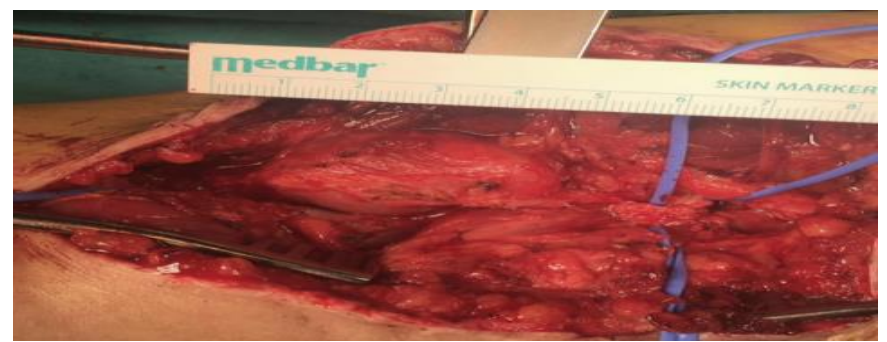

Resim 1: popliteal anevrizmanın uzunluğu

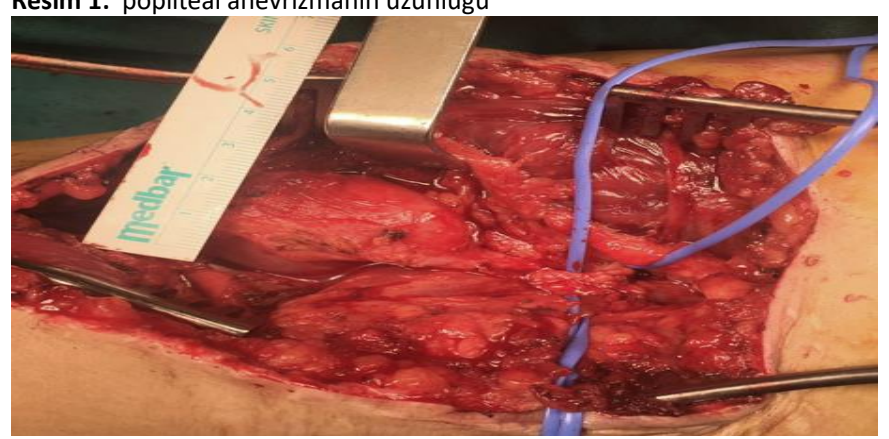

Resim 2: popliteal anevrizmanın genişliği

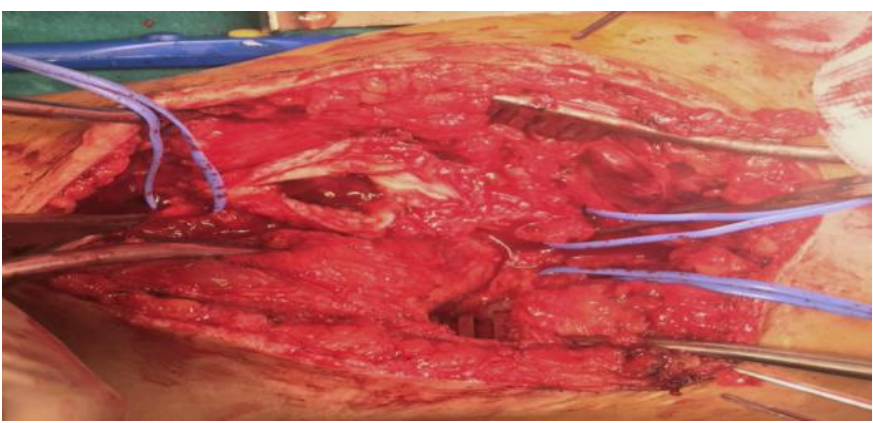

Resim 3: popliteal anevrizma eksizyonu

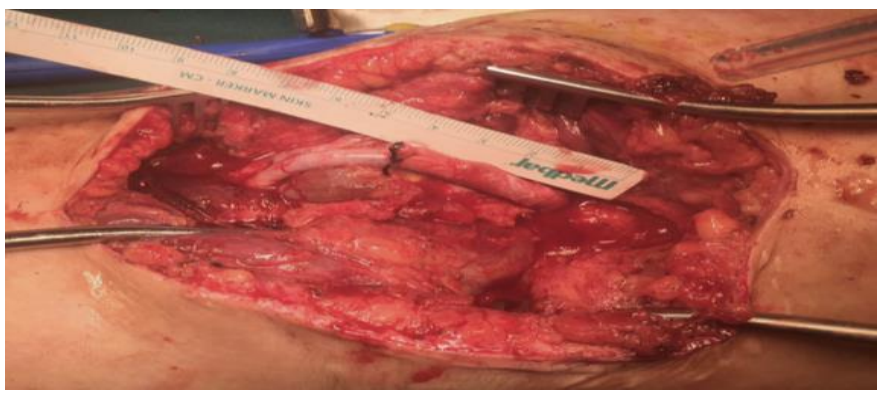

Resim 4: İliak homogreftin popliteal interpozisyonu

\section{SONUÇ}

Anevrizmalar sıklıkla belirti vermeyen ancak hayatı tehdit edebilecek kadar ciddi komplikasyonlara yol açabilen durumlardır. Anevrizma tamirinde büyüme çağındaki hastalarda sıklıkla otolog vasküler greftler kullanılırken, erişkin hastalarda bu seçeneğe ek olarak sentetik greftler de gündeme gelmektedir. Ancak büyüme çağındaki hastalarda anevrizmatik segmentin de büyümeyle ilişkili olarak genişlemeye devam edebileceği unutulmamalıdır. Böyle durumlarda ince duvarlı ven greftleri kullanmak yerine homogreft arter kullanmak, uzun vadede daha etkin bir tedavi seçeneği olabilir(5). Homogreft damar kullanımının artması için homogreft bankalarının ve homogreft hazırlama yöntemlerinin geliştirilmesine ihtiyaç vardır. Umuyoruz ki ilerleyen yıllarda, tromboz ihtimali daha yüksek olan sentetik greftlerin yerini, daha iyi doku uyumu sağlayan ve daha uzun süre açık kalabilen homogreftler alacaktır.

\section{Çıkar Çatışması}

Yazarlar herhangi bir çıkar çatışması bildirmemiştir.

\section{KAYNAKLAR}

1- Kumar V, ed. Robbins Basic Pathology (8th ed.). Philadelphia: Saunders/Elsevier. (2007).

2- Azar D, Ohadi D, Rachev A, Eberth JF, Uline MJ, Shazly T. "Mechanical and geometrical determinants of wall stress in abdominal aortic aneurysms: A computational study". PLOS One. 13 (2): e0192032, ( 2018).

3- Walker BR, Colledge NR, Ralston SH Davidson's principles and practice of medicine (21st ed.). Edinburgh: Churchill Livingstone/Elsevier. p. 604, (2010).

4- Joshi, D; James, RL; Jones, "Endovascular versus open repair of asymptomatic popliteal artery aneurysm". The Cochrane Database of Systematic Reviews. 8: CD010149 L (2014).

5- Luca et al. Treatment of Popliteal Artery Aneurysms by Means of Cryopreserved Homograft Mezzetto, Annals of Vascular Surgery, Volume 29 , Issue 6 , $1090-1096$ (2015). 